\title{
Antoine Robitaille
}

Journaliste au journal LE DEVOIR

(2002)

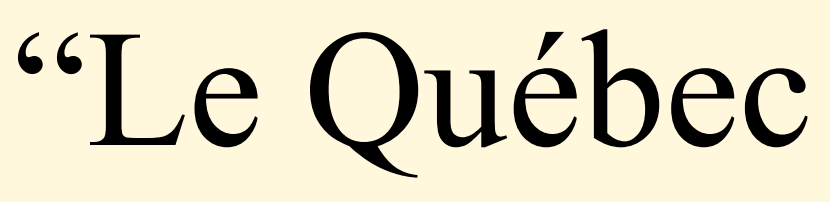

\section{ou le ground zero de la religion"}

\section{Entrevue avec Jacques Grand'Maison}

Un document produit en version numérique par Jean-Marie Tremblay, bénévole, Professeur sociologie au Cégep de Chicoutimi

Courriel: jean-marie tremblay@uqac.ca

Dans le cadre de "Les classiques des sciences sociales"

Site web: http://classiques.uqac.ca/

Une bibliothèque fondée et dirigée par Jean-Marie Tremblay, sociologue

Une collection développée en collaboration avec la Bibliothèque

Paul-Émile-Boulet de l'Université du Québec à Chicoutimi

Site web: http://bibliotheque.uqac.ca/ 
Cette édition électronique a été réalisée Jean-Marie Tremblay, bénévole, professeur de soins infirmiers retraitée de l'enseignement au Cégep de Chicoutimi

Courriel: jean-marie tremblay@uqac.ca

à partir de l'article de :

Antoine Robitaille, "Le Québec ou le ground zero de la religion". Montréal, Le Devoir, édition du samedi 5 octobre 2002.

L'auteur est journaliste au journal LE DEVOIR.

M. Jacques Grand'Maison (1931 - ) est sociologue (retraité de l'enseignement) de l'Université de Montréal.

[Autorisation formelle réitérée le 6 mars 2004 au téléphone par M. Jacques Grand'Maison et confirmée par écrit le 15 mars 2004 de diffuser la totalité de ses œuvres : articles et livres]

\section{Courriel : diocesesj@,citenet.net}

Polices de caractères utilisée :

Pour le texte: Times New Roman, 14 points.

Pour les citations : Times New Roman 12 points.

Pour les notes de bas de page : Times New Roman, 12 points.

Édition électronique réalisée avec le traitement de textes Microsoft Word 2004 pour Macintosh.

Mise en page sur papier format : LETTRE (US letter), 8.5' x 11'”)

Édition numérique réalisée le 8 mai 2006 à Chicoutimi, Ville de Saguenay, province de Québec, Canada. 
Antoine Robitaille,

"Le Québec ou le ground zero de la religion".

Montréal, Le Devoir, édition du samedi 5 octobre 2002.

Entrevue avec Jacques Grand'Maison à l'occasion de la publication du livre, RÉENCHANTER LA VIE publié aux Éditions Fidès en 2002.

À quelque 70 ans, le sociologue et théologien Jacques Grand'Maison vient de publier Réenchanter la vie, premier tome d'une grande étude visant à expliciter ce qu'il nomme le «discernement spirituel». Après avoir été fort critique à l'endroit de la société et affirmé que «le jugement fout le camp», il a décidé de se consacrer au «discernement spirituel», qui n'a pas toujours une expression religieuse, ainsi qu'aux «voies d'accès» qui y mènent.

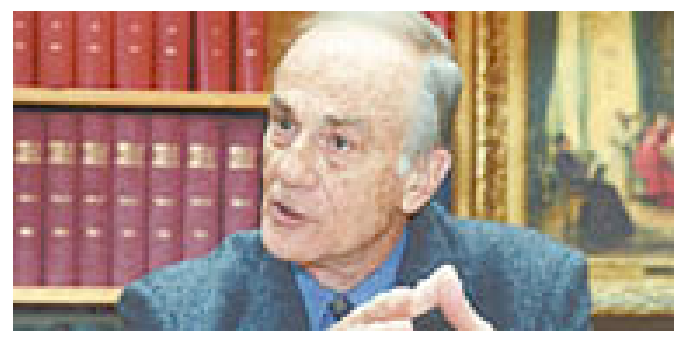

Jacques Grand'Maison (Photo de Jacques Grenier)

On a l'habitude d'entendre que le désenchantement du monde a été une conquête de liberté. Cela nous a débarrassés de bien des carcans.

Jacques Grand'Maison. Il y a eu désenchantement. On peut en faire une lecture nihiliste: tout enchantement apparait alors comme une illusion qui maintient l'esprit dans la pensée magique. Si on se reporte à ce procès historique du siècle des Lumières, on souhaite la victoire 
de la raison qui aura un jour raison sur tout. Mais aujourd'hui, il n'y a que quelques intellectuels qui sont enchantés du désenchantement, si vous me permettez la boutade. On est aussi désenchantés, aujourd'hui, des idéologies politiques des deux derniers siècles.

Le Devoir. Ces grandes idéologies n'étaient-elles pas des tentatives de réenchantement?

J. G. Certes. Mais aujourd'hui, il faut redécouvrir les forces de positivation de l'être humain, sa force d'espérance envers et contre tout. Comme le fait remarquer un auteur que j'aime bien : dans l'histoire humaine, la majorité des gens ont vécu des conditions souvent désespérantes; pourtant, très peu se sont suicidés ! Cette force est dans la vie même. Il y a eu cinq périodes dans l'histoire de la terre où la vie a été menacée de disparaître. La troisième est la plus évidente : $90 \%$ des espèces ont disparu. Mais la vie l'a emporté. Cette force de positivation au coeur de l'expérience humaine, on en parle très peu, parce qu'on a développé une modernité qui porte en elle-même ses propres ferments critiques. C'est un trait intéressant, mais ça ne nous empêche pas de faire le bilan positif des enrichissements des progrès humains qu'a apportés la modernité.

Le Devoir. L'esprit critique en est un.

J. G. Bien sûr. Et j'en nommerais d'autres : la revalorisation du corps, la qualité de vie, une affectivité plus saine, plus épanouie, l'enrichissement de la subjectivité, la famille moderne, qu'elle soit standard ou recomposée, permettent d'engager davantage sa propre histoire, la révolution. C'est tout un nouvel art de vivre qui s'est développé dans les sociétés occidentales et chez nous. Il y a aussi ce que j'appelle, moi, une gestation des consciences menant à la refondation des valeurs. Et ça, pour moi, c'est un progrès. Les droits humains fondamentaux, la société civile, une conscience plus mondiale, un renouement avec les profondeurs sociales et spirituelles. Et puis cette formidable créativité culturelle, en particulier chez nous.

Le Devoir. On oppose souvent modernité et religion. Chez nous cela va de soi puisque c'est la base de la Révolution tranquille. Mais quand on y regarde bien, il y a dans bien des peuples une religiosité 
qui coexiste avec une modernité peut-être assez grande. Est-ce une illusion québécoise que d'opposer comme ça religion et modernité ?

J. G. Même le mouvement laïque français fait un virage radical pour réintroduire l'enseignement de l'histoire des religions dans les écoles. Au même moment, ici au Québec, certains laïcismes ressemblent à des copies inversées d'un confessionnalisme étroit. Même dans le rapport Proulx sur la place de la religion à l'école, la dimension religieuse a pratiquement été réduite à zéro. On s'en va vers " ground zero $»$ ! On est pratiquement les seuls au monde à raisonner comme ça. Je comprends que la modernité s'est faite dans un mouvement d'émancipation de l'univers de la chrétienté. Mais la tradition judéochrétienne, elle a été marquée d'une centaine de cultures, de religions ! Or, chez nous, on entend toujours les mêmes discours simplistes qui réduisent tout cela à une " entreprise de culpabilisation ». C'est d'un simplisme inouï.

Le Devoir. Votre posture est celle de la modestie, dans ce livre. Vous parlez vous-même de votre "poésie à cinq sous ». Vous relativisez vos thèses. En même temps, c'est un livre d'une énorme ambition : réenchanter la vie, c'est tout un programme !

J. G. Je sais, mais justement, je me rends compte qu'il n'y a pas de foi sans modestie. Pour réenchanter la vie, il faut qu'on soit capable de recevoir autre chose que soi. Pour moi, le plus grave désenchantement, c'est la culture narcissique. On s'est rendu compte, dans notre recherche, qu'il y a beaucoup de suicides qui étaient imputables à cette culture narcissique de toute-puissance.

Le Devoir. Qu'entendez-vous par cela?

J. G. Une des spécificités du mythe de Narcisse, c'est qu'il n'est pas en amour avec son être réel mais avec son image, et l'autre doit être son miroir. Or, dans notre culture médiatique moderne, le narcissisme, c'est surtout être vu. Quand on n'a de choix qu'entre le sublime et l'abject, on ne peut être que dévoré ! Vous avez des suicides qui sont aussi des actes de toute-puissance liés au sentiment profond d'impuissance par rapport aux limites du réel. 
Le Devoir. Diriez-vous que c'est le cas du suicide de Dédé Fortin, que vous abordez dans le livre?

J. G. Je ne sais pas. Moi, j'en parle dans le contexte de la déculturation. Je trouve qu'il n'avait pas les mots pour exprimer ses bleus à l'âme. Vous avez aussi vu que je parle de ce groupe de parents pour qui tout a perdu son sens dans la société actuelle, cette impression qu'il n'y a plus de fondement.

Le Devoir. On sent, chez vous, beaucoup d'empathie à l'égard des jeunes. Je me suis demandé à un moment donné si vous n'auriez pas voulu être père vous-même.

J. G. J'ai tenté de vivre ma tâche d'éducateur comme une paternité. $\mathrm{J}$ 'y tenais. Les étudiants riaient au début, mais ils se sont rendu compte plus tard que ça avait une signification. On peut donc être père de ses propres enfants, mais il y a d'autres types de paternité. Moi, j'ai consacré ma vie aux enfants des autres, c'est pour cela que, lorsqu'on me demande ce que je connais à l'éducation, moi qui n'ai pas eu d'enfants, je réponds que j'ai éduqué des enfants pendant 50 ans, ce qui me permet de dire certaines choses.

Le Devoir. Pensez-vous qu'être célibataire a fait de vous un meilleur éducateur?

J. G. Non. Mais ça m'a donné plus de temps. La transmission de la culture, de la foi, c'est la passion de ma vie. Je n'aurais pu m'y consacrer complètement si j'avais eu femme et enfants. C'était assez clair dans mon pari de devenir un prêtre séculier, qui est dans le monde. D'ailleurs, je dirais qu'être un religieux n'était pas vraiment ce que je visais. Moi, les voeux d'obéissance. Pas que je méprise cela, mais. Non, si j'avais été père de famille, je n'aurais pu m'occuper des chômeurs comme je l'ai fait, par exemple, car il fallait travailler tard, aller voir ces gens-là où ils étaient : dans les bars, les salles de billards, etc.

Le Devoir. Avez-vous déjà eu envie de fonder une famille?

J. G. Oui. Je pourrais dire que ç'a été une des souffrances de ma vie que de ne pas avoir mes propres enfants. Mais en même temps, je ne 
peux pas dire que c'est une souffrance qui m'a jeté par terre, loin de là. J'ai vécu des rapports profonds, comme éducateur, avec mes élèves. J'ai tenté de vivre à fond ma paternité virtuelle. J'ai été tellement passionné par mon travail d'éducation, par les jeunes dont j'étais responsable, que je n'ai pas eu le temps de me décourager dans mes blessures et de fréquenter les instances de la société thérapeutique!

\section{RÉENCHANTER LA VIE}

Jacques Grand'Maison

Fides

Montréal, 2002, 287 pages

Fin du texte 